\title{
Science-based regulation of endocrine disrupting chemicals in Europe: which approach?
}

Endocrine disruptors are defined by WHO as "exogenous compounds or mixtures that alter function(s) of the endocrine system and consequently cause adverse effects in an intact organism, or its progeny, or (sub) populations". ${ }^{1}$ European Union (EU) laws on pesticides (plant protection products regulation [PPPR]) and biocide products regulation (BPR), enacted in 2009 and 2012, respectively, place restrictions on the use of active substances with severe forms of toxicity, including carcinogenicity, mutagenicity, reproductive toxicity, and endocrine disruption. Chemicals with such properties will in the future not receive authorisation for placement on the market as active substances in pesticide or biocide products. Compared with earlier EU law, these legal provisions are innovative in two respects: first, for the first time, pesticides and biocides with endocrine-disrupting properties are regulated; second, those with severe toxicities are regulated solely on the basis of hazard identification, and not by risk assessment, as previously. Hazard identification pinpoints a potential threat to health (eg, a chemical), which is further analysed in a process of hazard characterisation in terms of additional features such as species sensitivities, dose-response relationships, and others. Risk assessment relates the likelihood that an effect occurs to exposures experienced under different circumstances. ${ }^{2}$ This development requires that scientific criteria for the identification of endocrine disruptors are developed, and the European Commission (EC) was obliged by law to publish such scientific criteria within the context of PPPR and BPR by 2013.

Commercial interests have strongly argued against hazard-based cut-off criteria for endocrine disruptors, which resulted in the EC conducting an impact assessment before defining the endocrine disruptor criteria. ${ }^{3}$ Inevitably, this challenge has delayed the publication of criteria to such an extent that Sweden and other EU member states brought a case against the EC for not establishing the criteria. In December, 2015, the European Court of Justice judged that the EC acted unlawfully in failing to publish the criteria, and that an impact assessment was not necessary for their development. ${ }^{4}$ This judgment has been followed by a resolution adopted by the European Parliament on June 8,2016 . This resolution stresses that the criteria can only be carried out on the basis of scientific data related to the endocrine system, independently of any other consideration, particularly economic ones. Also, it calls on the Commission to immediately adopt hazard-based scientific criteria for the determination of endocrine-disrupting properties.

At the time of publication, the EC has not released the endocrine disruptor criteria and continues to justify this delay with reference to a controversy within the scientific community. ${ }^{5}$ However, we have recently shown that the controversy is not about the basics of endocrine disruptor science, but rather is the result of a lack of distinction between hazard identification and risk assessment (which is not required for the identification of endocrine disruptors as defined in the laws on pesticides and biocides). ${ }^{2}$ Very recently, this confusion was resolved, and a consensus among the scientists engaged in the previous debate has emerged, with all involved now accepting that the regulatory decisionmaking required in EU laws on pesticides and biocides involves hazard identification. ${ }^{6}$ We have also shown that endocrine disruptors can be identified through a scientific strategy analogous to that implemented for carcinogens by the International Agency for Research on Cancer (IARC; part of WHO). ${ }^{2}$ The first step in risk assessment is to identify whether a chemical or a mixture belongs to a given class of hazards, such as carcinogens. IARC identifies carcinogens and categorises the degree of confidence in this identification without regard to potency. No one would suggest making the definition of carcinogens dependent on an impact assessment, and the same should apply to endocrine disruptors.

Although a great deal is known about how hormones affect health and disease, there remains much to learn. Similarly, we know a great deal about how some manufactured chemicals can cause adverse effects in human beings, farm animals, and wildlife by interfering with hormones. ${ }^{7}$ Researchers have shown that endocrine disruptors can produce epigenetic modifications and transgenerational effects. ${ }^{8}$ Such scientific evidence must be considered appropriately
Lancet Diabetes Endocrinol 2016 Published Online June 13, 2016 http://dx.doi.org/10.1016/ S2213-8587(16)30121-8 
with respect to its implications for human health today and for future generations. Robust science at the leading edge allows us to discriminate among the known, the possible, and the unknown. Therefore, the decision taken by the EC should be based on what we know now, and allow incorporation of new information as it becomes available.

In a roadmap that the EC released in 2014 to define the parameters of impact assessment, four different options for defining regulatory criteria for endocrine disruptors were proposed. ${ }^{9}$ The first does not provide defining criteria, and is therefore not operable. Two options (labelled 2 and 3 ) rely on the WHO definition of endocrine disruptors; option 2 defines a single category of endocrine disruptors, whereas option 3 further identifies suspected endocrine disruptors and endocrine-
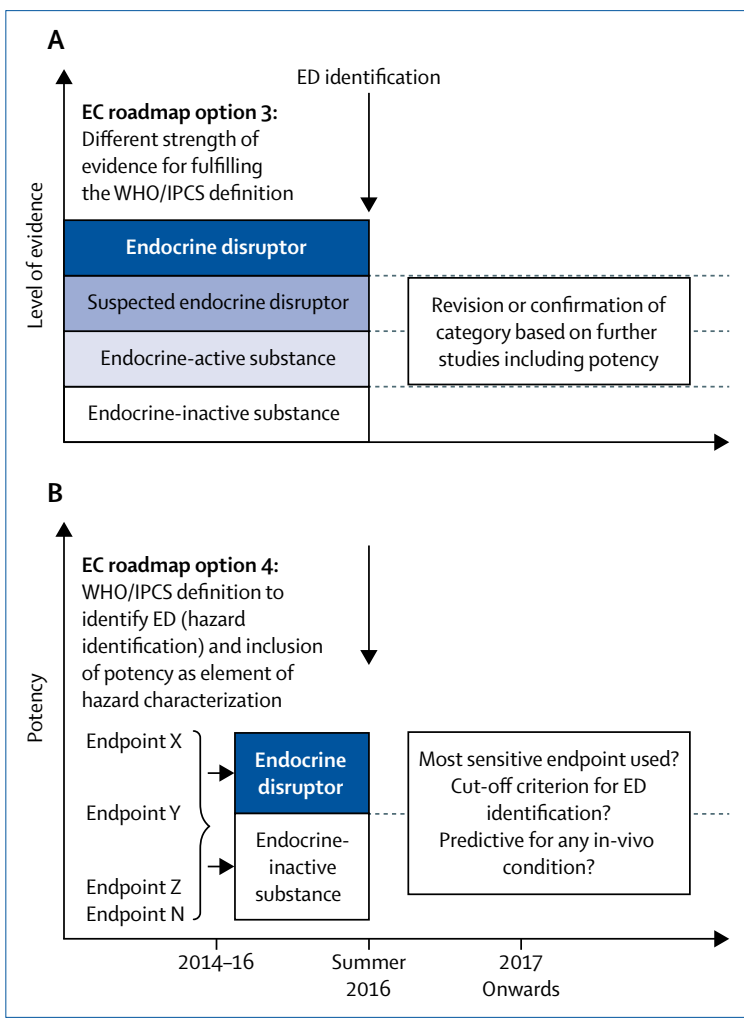

Figure: Two proposed options for identification of EDs in the European Union

In a 2014 roadmap, the European Commission has proposed criteria for ED identification through four options; here we show option 3 (A) and option 4 (B). From summer, 2016, EDs will be identified based on one option or the other. Option 3 identifies endocrine-inactive substances and three ED categories based on the level of evidence; it allows for further revision based on new scientific information. Option 4 uses potency as a criterion and identifies only one ED category; its application implies further questions about selected endpoints, cutoff criteria, and predictive value. In panel B, the four symbols arbitrarily denote different levels of potency of a given chemical depending on the studied endpoint $\mathrm{ED}=$ endocrine disruptor. IPCS=International Programme on Chemical Safety. active substances (figure). Such categories, based on level of evidence, are consistent with those used in the EU for carcinogens, mutagens, and reprotoxicants, which are hazards of equivalent concern to endocrine disruptors. Moreover, option 3 provides the necessary characteristics that will allow for incorporation of new data as it becomes available, which might trigger revised categorisations (figure). The majority of responders to the public consultation initiated by the EC about endocrine disruptor identification criteria were clearly in favour of option $3 .^{10}$ The Endocrine Society, the world's largest organisation devoted to research on hormones and the clinical care of endocrine disorders, also supports this option. ${ }^{11}$ An assessment of the strength of the evidence has also been used in studies on the cost of managing health consequences of endocrine disruptors in the EU; with more than $99 \%$ probability, this cost exceeds $€ 160$ billion per year. ${ }^{12}$

The last option (option 4; figure) uses a binary definition (endocrine disruptors or non-endocrine disruptors) and incorporates potency as a criterion. The idea of including potency was initiated by UK and German authorities. Mindful of the potential economic effect on industry of regulating substances with ED properties in a hazard-based system, the stated intention was to only assign the endocrine disruptor identifier to substances of high potency and where the endocrine disruptor property is a prominent feature of the hazard profile. ${ }^{13}$ Potency, however, is not mentioned in the accepted WHO definition ${ }^{1}$ and has been deemed irrelevant for the identification of endocrine disruptors. ${ }^{2}$ Potency is quite complex to apply as a criterion and scientifically indefensible because a single chemical might seem differently potent depending on the endpoint and the testing conditions (figure). Potency is measured by a dose-response function; however, the variability of the response and the corresponding likelihood of overlooking effects are what make potency so complicated. Historically, diethylstilbestrol and thalidomide are notable examples. These drugs were prescribed for pregnant women without any adverse effects being noted. However, the children of treated women showed adverse effects-either at the time of birth, or several years later. In these cases, the prediction of negligible potency from some in-vivo testing gave physicians the confidence to prescribe these drugs, but they were tragically missing crucial 
data for developmental issues. In a recent position statement about EU regulation of endocrine disruptors, the Endocrine Society recommended the exclusion of potency from identification criteria. ${ }^{11}$ Similarly, the consensus statement from the scientists engaged in the previous debate over scientific principles for the identification of endocrine disruptors states that potency considerations have no place in the hazard identification process for endocrine disruptors. ${ }^{6}$

The current scientific consensus on the relevance of the WHO definition of endocrine disruptors, ${ }^{1}$ the irrelevance of potency for the identification of endocrine disruptors, ${ }^{2,6}$ and the inapplicability of impact assessment studies to provide scientific definition of endocrine disruptors ${ }^{2,11}$ all point to the same conclusion. As scientists, we believe that science provides all necessary arguments towards implementation of relevant criteria to identify endocrine disruptors. Such criteria are consistent with an option already formulated by the EC: option 3 of the EC roadmap. Public health urgently deserves science-based regulations.

\section{*Jean-Pierre Bourguignon, Rémy Slama, Åke Bergman, Barbara Demeneix, Richard Ivell, Andreas Kortenkamp,} GianCarlo Panzica, Leonardo Trasande, R Thomas Zoeller Pediatric Endocrinology, CHU Liège and Neuroendocrinology Unit, GIGA Neurosciences, University of Liège, B4000 Liège, Belgium (J-PB); Inserm, CNRS and University Grenoble Alpes, IAB Joint Research Center, Team of Environmental Epidemiology, Grenoble, France (RS); Swedish Toxicology Sciences Research Center, Södertälje, Sweden (ÅB); UMR CNRS/MNHN 7221, Department RDDM, Muséum National d'Histoire Naturelle, Paris, France (BD); School of Biosciences \& School of Veterinary Medicine and Science, University of Nottingham, Nottingham ,UK (RI); Brunel University London, Institute of Environment, Health and Societies, Uxbridge, UK (AK); Department of Neuroscience, University of Torino, and Neuroscience Institute Cavalieri Ottolenghi, Orbassano, Italy (GP); Departments of Pediatrics, Environmental Medicine and Population health, New York University School of Medicine, New York, NY, USA (LT); and University of Massachusetts, Biology Department, Amherst, MA, USA (RTZ)

jpbourguignon@ulg.ac.be

$\mathrm{BD}$ is a cofounder of the company WatchFrog, , a producer of fluorescent amphibian larvae for detection of chemicals. The other authors declare no competing interests. J-PB, RS, BD, RI, GCP, LT, and RTZ thank the Endocrine
Society for organisational support and reimbursement of travel expenses related to meetings about incorporation of endocrine science data into the regulatory management of endocrine-disrupting chemicals.

1 WHO. Global assessment of the state-of-the-science of endocrine disruptors. WHO/PCS/EDC/02.2. http://www.who.int/ipcs/publications/ new_issues/endocrine_disruptors/en/ (accessed June 2, 2016).

2 Slama R, Bourguignon JP, Demeneix B, Ivell R, Panzica GC, Kortenkamp A, Zoeller RT. Scientific issues relevant to setting regulatory criteria to identify endocrine disrupting substances in the European Union. Env Health Perspect 2016; published online April 25. DOI:10.1289/EHP217.

3 Horel S. A toxic affair: how the chemical lobby blocked action on endocrine disrupting chemicals. Brussels: Corporate Europe Observatory, 2015. http://corporateeurope.org/food-and-agriculture/2015/05/toxic-affairhow-chemical-lobby-blocked-action-hormone-disrupting (accessed June 2, 2016).

4 European Parliament resolution of 8 June 2016 on endocrine disruptors: state of play following the judgment of the General Court of the European Union of 16 December 2015 (2016/2747(RSP). http://www.europarl. europa.eu/sides/getDoc.do?pubRef=-//EP//TEXT+TA+P8-TA-2016$0270+0+D O C+X M L+V 0 / / E N \& l a n g u a g e=E N($ accessed June 8,2016$)$

5 European Commission. EC Commissioner Andriukaitis, Statement to the European Parliament Plenary, Feb 2, 2016-Commission statement Commission action to comply with Judgement in case T-521/14: Sweden vs the Commission. https://ec.europa.eu/commission/2014-2019/ andriukaitis/announcements/ep-plenary-commission-statementcommission-action-comply-judgement-case-t-52114-sweden-vscommission_en (accessed June 2, 2016).

6 BfR. Scientific principles for the identification of endocrine disrupting chemicals - a consensus statement. Outcome of an international expert meeting organized by the German Federal Institute for Risk Assessment (BfR). Communication 011/2016. http://www.bfr.bund.de/en/publication/ bfr_opinions_2016-196132.html (accessed June 2, 2016).

7 UNEP/WHO. State of the science of endocrine disrupting chemicals. Geneva: World Health Organization, United Nation Environmental Program, 2013. http://www.who.int/ceh/publications/endocrine/en/index. html (accessed June 2, 2016).

8 Skinner MK, Manikkam M, Guerrero-Bosagna C. Epigenetic transgenerational actions of endocrine disruptors. Reprod Toxicol 2011; 31: 337-43.

9 European Commission. Roadmap-defining criteria for identifying endocrine disruptors in the context of the implementation of the plant protection product regulation and biocidal products regulation. Brussels: European Commission, 2014. http://ec.europa.eu/smart- regulation/ impact/planned_ia/docs/2014_env_009_endocrine_disruptors_en.pdf (accessed June 2, 2016).

10 European Commission. Report on public consultation on defining criteria for identifying endocrine disruptors in the context of the implementation of the plant protection product regulation and biocidal products regulation. Brussels: European Commission, 2015. http://ec.europa.eu/ health/endocrine_disruptors/docs/2015_public_consultation_report_e $\mathrm{n}$. pdf (accessed June 2, 2016).

11 Endocrine-disrupting chemicals in the European Union Endocrine Society, 2015. https://www.endocrine.org/ /media/endosociety/files/advocacyand-outreach/position-statements/2015/position_statement_edc_eu.pdf (accessed June 2, 2016).

12 Trasande L, Zoeller RT, Hass U, et al. Estimating burden and disease costs of exposure to endocrine-disrupting chemicals in the European Union. J Clin Endocrinol Metab 2015; 100:1245-55.

13 BfR. German Federal Institute for Risk Assessment). Joint DE - UK position paper. Regulatory definition of an endocrine disrupter in relation to potential threat to human health. Proposal applicable in the regulatory context of Plant Protection Products, Biocidial Products, and Chemicals targeted within REACH. May 16, 2011. http://www.bfr.bund.de/cm/343/ regulatory_definition_of_an_endocrine_disrupter_in_relation_to_ potential_threat_to_human_health.pdf(accessed June 5, 2016) 